\title{
500 Centenario de Martín Lutero
}

\author{
Un hombre sensible. Circunstancias
}

El papado se convierte en institución garantizada tanto por los dominios pontificios como por las altezas, majestades, órdenes mendicantes y clero. La escolástica estudia lo espiritual con santo Tomás de Aquino, Egidio Romano y Santiago de Viterbo. Quienes confesaban leer a san Agustín ofrecían obras teológicas, de espiritualidad y filosofía. El pensamiento orienta la obediencia hacia la sede apostólica. El centralismo de los romanos pontífices choca con las fuerzas galicanas interiores en cada «Estado» naciente. Roma adoctrina el universalismo y Maximiliano, el emperador, temporiza con los deseos y compromisos de la Corona titulada: Sacro Romano Imperio. Los obispos de Alemania, siendo príncipes defensores de privilegios anteriores a Carlomagno, «obedecen» al Obispo de Roma quien hasta les había impuesto inquisidores. La solidaridad entre eclesiásticos era mantenida siempre y cuando los intereses económicos no tambalearan el poder y autoridad tradicional y las curias tuviesen lo sufiente para continuar ofreciendo rezos en las catedrales y mesas.

Las órdenes mendicantes pretendían aprender doctrinas anteponiendo la tela del hábito «entregado» por la Virgen. La leyenda respondía a las preguntas y la dialéctica de las discusiones impone métodos convirtiendo los silogismos en razonamientos de verdad. El latín de los clérigos ofrece una "clase» y los libros son publicados en la lengua de la «Iglesia». El «laico» es «salvado» por medio de obras y gracias cuyo «tesoro» está en la iglesia. Los «sacerdotes» tienen la facultad delegada de dispensar los «méritos» de otros y la dependencia colosal es absolutamente obligatoria so pena de caer en excomuniones, cárceles y ser condenados incluso al fuego como lo había sido Juan Hus durante el Concilio de Constanza.

Hijo de Maximiliano de Austria y de María de Borgoña, Felipe I el Hermoso, en 1496 acepta el matrimonio con la hija de los Reyes «Católicos» de España, país desde donde habían salido las naves de los «descubridores». La fór- 
mula «cuius regio eius religio» es aceptada y esos Reyes "Católicos» logran casar a Catalina de Aragón con el rey de Inglaterra Enrique VIII. Los reyes de España casando a hijos e hijas parece que aúnan las tierras de Europa en coronas de familia. El Papa les bendice y la Inquisición colabora a fortalecer la autoridad central. Las leyes «laicas» penalizan hechos de los que grupos poderosos sacan interés. La Inquisición presenta la mano fuerte y en «nombre de Dios» son cometidas las mayores atrocidades ante la mirada impasible de los «amantes de la verdad».

El cardenal Cisneros, en España, logra publicar la Políglota para «cultos» $y$ algunas Biblias son leídas en «lingua vulgaris». El pueblo conoce la dificultad de penetrar en los misterios religiosos, pero los humanistas, como Erasmo de Rotterdam, aconsejan la vuelta a los clásicos y el Papa León X, coronado cuando Lutero tenía 30 años (1513), abre camino en el Vaticano a Rafael, Miguel Ángel... Las manifestaciones externas y apariencias majestuosas en el culto, pintura y edificios, interpretan las ansias de la autoridad discutida.

Los estudios jurídicos abren a Martín Lutero el camino de Roma, ¿encontrará en las leyes respuesta y método? La ley señala caminos sociales y positivos, pero de ninguna manera conduce a la gracia. Quiere el jurista cumplir y la angustia de la falta personal más el desconcierto en sus circunstancias, le encaminan hacia donde cree encontrar rayos de luz tras los pasos de la doctrina agustiniana. Teniendo 22 años es aceptado como religioso agustino y desde 1508 enseña teología en Wittenberg. El hombre sensible a cuanto le rodea sufre ante la ignorancia y con celo de enseñar estudia más y más las Sagradas Escrituras. Escucha y lee, investiga y descubre, medita y acepta las penitencias, promete y culpa. La angustia al principio es jurídica, pues, quebrantando una ley un juez equitativo y justo le castigará. Este remordimiento y castigo, pena y tiempo de prueba le atemorizan. Descubre que quebranta una ley, merece castigo y antes de cumplir la condena ha cometido muchos otros "delitos». La angustia de permanecer en constante "cárcel» es aterradora. Aparentemente los «teólogos» y «juristas» no le presentan otra alternativa. Así era el interior de la autocrítica. Unos le hablan de esperanza, creer y salvarse, cumplir con una serie indefinida de preceptos, estatutos y mandamientos. Siendo consciente de las faltas personales y otras la desesperación del hombre responsable estaba a la punta de la mente.

La crisis personal beneficia soluciones y estudia, estudia y medita hasta que lee repetidas veces las Cartas de san Pablo y las Obras de san Agustín. Las alegrías interiores ante el descubrimiento de soluciones ayudan a los discípulos y todos agradecen la misericordia y amor de Dios. 


\section{Las indulgencias}

Existen autoridades eclesiásticas competentes para distribuir el «tesoro espiritual de la Iglesia» capaz de remisión «ante Dios la pena temporal debida por los pecados que ya han sido perdonados en cuanto a la culpa... remisión que la autoridad eclesiástica... concede a los vivos a manera de absolución y a los difuntos a manera de sufragio» (canon 911).

El tema de las indulgencias es un apartado o capítulo del título que el Derecho dedica a la penitencia. La tradición eclesiástica aceptó la práctica de las penas públicas y la reparación usada en otras instituciones. El interés del castigo queda sin contenido y cambian la pena física por otras sin publicidad, pero aptas a cualquier empresa de relaciones públicas. Las visitas a iglesias, el rezo de ciertas oraciones, la práctica de obras de "caridad», las peregrinaciones, la compra de bulas, documentos y participaciones específicas a mandatos de autoridades concretas, conseguían por medio de indulgencias la remisión de la pena temporal debida ante Dios por los pecados.

El romano pontífice constata las necesidades inminentes y concretas. La iglesia o basílica del Vaticano, la catedral de Maguncia... consumen trabajo y a los obreros hay que animarlos con algo más que indulgencias. Las participaciones continuas de los «obreros» eclesiásticos, no siendo suficientes, orientan los beneficios de la remisión de los pecados hacia el templo más largo de la cristiandad. Los fieles prefieren sacrificar lo necesario del alimiento antes que soportar el oprobio de permanecer públicamente como castigados. La pena, aunque sea por causa justa, deja huella. Los pobres apenas tenían capacidad económica para comprar el documento remisor. Los «ricos» con facilidad respondían a la llamada y confiados en el papel abandonan el esfuerzo. Los obispos poco reciben de los tesoros entregados por el pueblo y los «mendicantes», obedientes al romano pontífice, se gloriaban de entregar la solidaridad. ¡El repartidor de las indulgencias por los «méritos» de Cristo exige dinero!

El jurista y teólogo fray Martín Lutero contempla los hechos. En el Evangelio lee que Jesús expulsa a los «mercaderes del templo». La injusticia, es decir, la admisión de «clases» según la riqueza nunca había sido admitida y menos los privilegios. La acumulación de capital en el Vaticano no era equitable con la vida cotidiana de los fieles. La pomposidad medieval y el gasto superfluo en el culto no correspondían a los ejemplos de quien murió en una cruz. La solidez de la Iglesia no dependía de las piedras ni del volumen, sino de la obra de Cristo quien no tuvo dinero para comprar su sepultura y tampoco dejó en ella los huesos.

El derecho y la teología asocian los pensamientos del agustino Lutero 
quien comenta en comunidad el hecho de la predicación de las indulgencias. Como si fuesen cánones por su concisión y claridad escribe 95 tesis o enunciados y las expone sobre la puerta de la iglesia de la Universidad (31.X.1517). Los alumnos conocedores del asunto leen y copian, los impresores publican y la doctrina de las 95 tesis es el primer testimonio de prueba que los acusadores del agustino presentan gritando calumnias, porque no aceptaban el propio orgullo e ignorancia.

El teólogo Johannes Eck grita al escándalo y el cardenal Cayetano recibe la Bula «Cum postquam» (9 nov. 1518). La doctrina de las indulgencias y la potestad sobre las llaves de los sucesores de san Pedro son especificadas.

Fray Martín Lutero recibe acusaciones y hasta le amenazan con la condena. La comunidad agustiniana escucha y el superior, Juan de Staupiz, dialoga. Las doctrinas expresadas no eran contrarias a las enseñanzas del Evangelio, Cartas de san Pablo ni de los Santos Padres. Los errores en el método o enseñanza serían posibles, pero no aceptados sin prueba. Los contrarios, puesto que acusaban, debían probar. Los teólogos del Vaticano, no siendo agustinos y éstos aceptando la libertad como uno de los dones más importantes, de ninguna manera obligarían a castrar la inteligencia de un miembro de la comunidad.

Fray Martín Lutero sospecha la lluvia de acusaciones que caerán sobre él y cuantos se solidarizan a su método y prepara la defensa. Reúne testimonios, testigos, documentos, y quiere convencer y probar no sólo la inocencia personal, sino que es consciente sobre la necesidad de aclarar muchos temas de la doctrina eclesiástica y renovar o reformar la manera de presentar el Evangelio. Los argumentos de la parte contraria eran acumulados con el fin de refutarlos uno a uno y el estudio sobre la prueba de la verdad consigue conclusiones capaces de descubrir el renacimiento o vuelta hacia la enseñanza de las Sagradas Escrituras y Santos Padres. San Agustín, como el mejor conocedor de la doctrina paulina $y$ defensor de la vuelta hacia Cristo "Camino, Verdad y Vida», será el guía del religioso agustino.

El Papa León X escucha los argumentos de los contrarios y publica la Bula «Exurge Domine» (15 junio 1520). Los artículos calificados como «errores» son condenados, pero algunos de ellos quizá no fuesen ni escandalosos. EI punto de partida o «sentencia» dada sin escuchar al «reo» estaba formulada y los contrarios predican y «dogmatizan» sobre temas que ningún Concilio había definido. La propaganda de los contrarios abrió camino a la enseñanza de Lutero y los fieles comienzan a estudiar. 
La penitencia

El sacramento de la penitencia y la doctrina sobre la potestad de perdonar requieren un mandato específico de cuyo cumplimiento es necesario dar cuenta. La «autoridad» no debe salirse de lo que le han encomendado y las interpretaciones de la ley favorables a quien la dicta serán estrictas. El sacerdote obtiene la delegación de perdonar no en nombre propio, ya que tales faltas son del orden divino. El orden humano tiene sus jueces activos siempre y cuando el hecho sea probado o existan sospechas suficientes que aconsejen una instrucción. En orden divino actúa de manera diferente. Los hechos contrarios a lo sobrenatural no necesitan testigos para ser castigados, pues Dios sabe y ve todo, conoce al hombre y sus pecados, descubre las fuerzas de cada ser humano y las diferencias. Pretender probar algo a Dios es peor orgullo que el de Lucifer y el monje agustino constata el perdón, las penas y la remisión por medio de documentos pagados. ¿No es impío comprar con dinero la falta contra el orden sobrenatural? El soborno es alimento de miserables. Fray Martín estudia el tema del perdón y es consciente de que a él, caso que la salvación dependiese de sí mismo, de ninguna manera le serán remitidos los pecados, pues, peca constantemente. Lee en el Evangelio que el perdón pedido en verdad es adquirido «setenta veces siete».

Los «humanistas» y «pelagianos» de su época acuden a la voluntad y ascética pretendiendo convencer a Dios y hasta tratan de probar que ellos, con tales o cuales "ejercicios», son capaces de atraer la gracia, la fe y disposición de justicia. Lutero sabe que él no es capaz y quiere conocer cómo los demás consiguen lo que dicen. El punto de partida, siendo diferente, los «fuertes» le declaran la guerra e insultan. Él tampoco queda muy atrás en los insultos y el honor de todos entra en la confusión sin personas equitables capaces de neutralizar o ser árbitros. El papado estaba comprometido con una Bula, el Emperador Carlos $V$, después de la muerte de su abuelo Maximiliano, gracias al dinero recibido en La Coruña y a la cesión de Federico de Sajonia, compra la Corona y es elegido Emperador de Alemania (1519). Enrique VIII de Inglaterra aconseja al Emperador la lucha y persecución contra Lutero y en Aquisgrán los obispos de Colonia, Maguncia y Tréveris coronan a Carlos $\mathrm{V}$ como rey de los Romanos.

La comunidad de los agustinos, no pudiendo soportar las presiones, se divide, y Lutero deviene la "cabeza de turco» de todos.los males. Él es consciente de la debilidad personal y acude a las Sagradas Escrituras. El sacerdocio le vuelve las espaldas y penetra en el misterio de Cristo. Los escritos defensivos rompen el equilibrio y siendo un teólogo docto y lógico prueba razonadamente las conclusiones jurídicas. 
El Elector, Federico de Sajonia, descubre la fuerza de la autocrítica en Lutero, y Carlos $\mathrm{V}$ le envía un salvoconducto para que acudiese a la Dieta de Worms (1521). El canciller no escucha las pruebas y pide una retractación. «Eso no me lo permite mi conciencia» le contestó Martín Lutero.

La conciencia y el trabajo personal, la responsabilidad y la confianza en la obra de Cristo llenan la penitencia y alegría que el profesor de Witenberg expone. El castillo de Wartburgo atesora la ciencia de Lutero y en el silencio libre y custodiado traduce el Nuevo Testamento en Alemán. La imprenta, publicando tan maravilloso texto, divulga el pensamiento y el pueblo descubre el Evangelio. Los monopolios caen y los fieles estudian argumentos. Las discusiones salen a la calle y el respeto hacia quienes pretendían tener el monopolio disminuye. El temor y las penas son atenuadas con la traducción y los fieles exigen la vuelta a la Biblia. El Evangelio enseña y las personas aprenden la obra de salvación. Unos leen la plegaria del «publicano» y del «fariseo» y cada uno pasa al lado que más seguridad le ofrece.

El hombre, presentado ante Dios, es poca cosa y Lutero comienza a escribir o reestudiar la base de la Iglesia y se desolidariza del compromiso en orden a fundar el Vaticano sobre piedras colosales. Las penas caen y él afianza más la conciencia edificando con el apoyo de san Pablo y san Agustín la doctrina de la fe y justificación. Los «pelagianos» escandalizados acuden al orden y disciplina de los ejércitos. Lutero sabe que el perdón no depende de las armas aunque quien las maneje sea un diestro.

La teología de la cruz, tan querida por san Pablo, vuelve a ser de la época. Quien peca lo sabe y no necesita casuísticas y sí escuchar al Maestro interior. El hombre en lo sobrenatural asciende y es aceptado, siendo consciente de que vive por Cristo.

El perdón es un acto de amor, vuelta, conciencia de cómo se es y Dios en su Hijo ha perdonado a cuantos creen en Él.

El misterio de la cruz resuelve las dificultades de la predestinación y no necesita al sacerdote, es decir, tal sacerdote como un mandato específico para perdonar los pecados. El hombre - sacerdote- papa está en el mundo amando gratuitamente a Dios, pues el Padre lo ha amado sin méritos, pero se alegra en él una vez que la persona crea en el Hijo.

La fe

En las obras: Comentario sobre la Carta a los Gálatas, Comentario sobre la Carta a los Romanos, De servo arbitrio, Grande y Pequeño Catecismo, Llamada a la nobleza cristiana, La cautividad de Babilonia... explica las motivaciones sobre la doctrina que enseña. Las citas que hace tanto de la Biblia co- 
mo de san Agustín son exactas. Rara vez olvida confirmar cualquier conclusión con documentos de la epístola a los Gálatas, a los Romanos, a los Efesios, etc. Cada pensamiento es probado utilizando el método de la defensa y por ello convence no con silogismos y sí con pruebas. Hablando de la fe conoce la definición paulina: «Es la fe una convicción de las cosas que se esperan» ". "Sin fe es imposible ser grato» ${ }^{2}$.

«Sí, que por la gracia habéis sido salvados mediante la fe, y esto no de vosotros, que de Dios es el don. No es virtud de obras, para que nadie se gloríe ${ }^{3}$.

«Renovatio vitae inchoatur a fide qua creditur in eum qui justificat impium» ${ }^{4}$. La fe, en la obra De Trinitate, conduce al amor que deviene del conocimiento ${ }^{5}$. La persona conoce y ama a Dios. «Tu excitas, ut laudare te delectet, quia feciste nos ad te et inquietum est cor nostrum, donec requiescat in te ${ }^{6}$. «Invocat te Domine, fides mea, quam dedisti mihi, quam inspirasti mihi per humanitatem Filii tui» ${ }^{7}$.

La fe no es una virtud más, sino que con ella el hombre es salvado. No es algo abstracto, sino concreto, pues es vivir con Cristo, y tener la convicción de la obra consumada en la cruz.

Martín Lutero no cita a escolásticos y tampoco el método, y algunos creyeron que era un hereje.

\section{Justificación}

«Por el extremado amor con que nos amó, aunque estábamos nosotros muertos por los pecados, nos vivificó con la vida de Cristo» ${ }^{8}$. "porque en él tuvo a bien Dios que morase toda la plenitud y por medio de él reconciliar todas las cosas consigo ${ }^{9}$, pues, Jesús es «jefe iniciador y consumador de la fe» ${ }^{10}$. «En él habita la plenitud de la deidad corporalmente y vosotros en él estais cumplidamente llenos» ${ }^{11}$.

1. Epístola a los Hebreos, 11,1. Edición BAC.

2. Id. 11,6 .

3. Epístola a los Efesios, 2,8-9.

4. De Trinitate, IV, 3,5. Edición BAC.

5. Id. VIII, 4,6 .

6. Confesiones, 1, 1,1.

7. Id.

8. Efesios, 2,5.

9. Colosenses, 1,19-20.

10. Hebreos, 12,2.

11. Colosenses, 2,9 . 
«Tengo certeza de que no hay alma alguna en el género humano que no necesite para su liberación del Mediador entre Dios y los hombres, el Hombre Cristo-Jesús» ${ }^{12}$. "Que la elección de la gracia no se realice por ningún mérito precedente de obra, lo manifiesta con toda claridad el mismo Apóstol» ${ }^{13}$.

Cristo

El Camino, la Verdad y la Vida es Cristo. El Mediador, Verbo, Verdad eterna, principio y fin llena la vida de gracia. El hombre, siendo pecador, es redimido por el Justo. «Ahí tienes hecho a Dios hombre por ti y tú con serlo ¿no quieres reconocerte hombre? Hízose por ti hombre sin pecado y ¿no quieres reconocerte pecador para ir a quien dice: Venid a mí? ${ }^{14}$. Cristo es Mediador de vida, es la Vida, es la Presencia, el todo y el hombre «muerto en el alma por el pecado» ${ }^{15}$ necesita a Cristo. La necesidad es absoluta y conditio sine qua non. El hombre sin Cristo no tiene posibilidad alguna para presentarse al Padre. El hombre, tal hombre en el orden sobrenatural, de salvación, necesitó al Hijo de Dios para ser redimido. Ahora con la fe, es decir, con Cristo, es decir, justificado en la Cruz y muerte del Hombre todo divinidad y humanidad, justo e Hijo de Dios, con plena confianza existe capacidad suficiente para presentarnos ante el Padre.

«No neguéis la gracia de Dios, ni defendáis la libertad de manera que la separéis, como si por alguna razón sin ella (podéis) pensar o hacer algo según Dios. En ninguna manera lo podemos» ${ }^{16}$. Todo lo podemos en Cristo, pues, «Cristo nuestro Señor vino a nosotros, por nosotros, cuando, siendo justo, encontró a los pecadores» ${ }^{17}$. El pecado ha sido eliminado por el Justo y reconciliador. Ahora caminamos y uen este camino de la fe hagamos el bien y para hacer el bien tengamos hacia Dios un afecto gratuito y hacia el prójimo un afecto benéfico» ${ }^{18}$. «Perdonándonos reciprocamente, así como Dios en Cristo os perdonó a vosotros» ${ }^{19}$.

La relación directa entre el hombre y Cristo Camino hacia el Padre y la fe son la constante enseñanza de san Pablo, san Agustín y Martín Lutero. El amor, la «sola gratia et sola fide», la libertad, el trabajo, la confianza... tienen

12. Epístola a Jerónimo, cap. 1, n. 5, p. 469. Edición BAC.

13. Epístola a Sixto, Edic. BAC, p. 835, n. 39.

14. Sermón 30, n. 9, p. 695. Edición BAC.

15. De Trinitate, IV , 7, n. 11, p. 345. Edición BAC.

16. Epístola 214, A Valentín, p. 1003, n. 2.

17. Epístola 205, p. 961, n. 11.

18. Sermón 91, p. 555, n. 9.

19. Efesios, 5,8 . 
referencia a Cristo. El mundo necesita y ha sido reconciliado en Cristo. He ahí la fuerza del lleno de Cristo Martín Lutero quien, como él confiesa, en cuanto hombre no es mejor que los demás.

\section{Martín Lutero}

El hombre tuvo defectos y grandes, él fue consciente y quiso evitarlos, pero quien se crea limpio que eche la primera piedra, Cristo escribirá sobre el polvo apareciendo la hipocresía de los acusadores. No califico defecto el hecho de que se casase y tuviese hijos a quienes quiso con ternura. El caminó con un temperamento y siendo quien era defendía una causa. El hecho de que fuese abogado le facilitó la autodefensa y nadie le culpe de aparecer colérico y convencido en el momento de la defensa. Lutero defiende la causa de Cristo y del Evangelio con los medios de un hombre redimido por el Hombre Justo. La redención no había sido de otra manera que muriendo voluntariamente en una cruz. Cualquier abogado pone celo y todo el peso de la ciencia para defender la obra del Hijo de Dios hecho Hombre por él. ¿Comprenden a Lutero? Es verdad que existieron faltas contra el honor, es decir, injurias, difamaciones y hasta calumnias, pero también los defensores de la «Tradición» cometieron tales delitos. Lutero faltó en el momento de la defensa y respondiendo a las acusaciones. No olvidemos que fue condenado. Tradicionalmente, en las Facultades de teología y otras, con sadismo y mentira algunos profesores calumnian aún hoy al hombre lleno de fe, Martín Lutero. Doy gracias a Dios que tuve el honor de estudiar y formarme con los agustinos, donde siempre han existido y existen sabios amarrados a la doctrina de la Biblia y de los Santos Padres.

San Agustín pide la vuelta constante al Principio y él hizo una comunidad pensando en los primeros cristianos. La tradición de volver y acomodarse a la circunstancia es una orientación muy agustiniana y Lutero la cumplió.

La doctrina expresada en líneas anteriores es de san Pablo y san Agustín. Expresamente no he querido citar textos de Lutero, pues en nada desdicen y sí explican con más claridad lo escrito. Las aclaraciones del Concilio de Trento habrá que estudiarlas conforme a las circunstancias y el significado de las palabras. No olvidemos que Seripando, otro gran agustino, hubiese evitado separaciones y condenas. Tan sólo podemos decir: Dios escribe recto con líneas torcidas. Quizá el respeto hacia el otro hoy reconcilie a los «enemigos».

La teología de la Cruz y la fe en la obra que deviene del cumplimiento realizado por Cristo, resume la doctrina de Martín Lutero. El bien pertenece a Dios y el justo vive por la fe. ¿Existe do ut des con Dios? ¿Quién se ha creído ser el hombre? Lo sublime es la «Venida» del Hijo y en, con y por él somos 
aceptados. Las obras tienen una finalidad infinita, no en tanto que nuestras y sí porque somos hijos adoptivos de Dios.

La confianza es indefinida, pues, el hombre consciente de lo que es sabe la realidad infinita que le espera. La vida es un caminar alegre y seguro.

El lema de Lutero: Cuando se tiene la Cruz en el corazón éste descansa sobre una rosa, no sólo es una fórmula lograda, sino también toda la espiritualidad.

Leandro RODRIGUEZ

Ginebra 